\title{
Improving the Use of Robotic Welding of Aluminum Boats through Modularization
}

\author{
Paul Kah, Esa Hiltunen, Jukka Martikainen \\ Laboratory of Welding Technology, Department of Mechanical Engineering, \\ Lappeenranta University of Technology, Lappeenranta, Finland \\ Email: paul.kah@lut.fi
}

Received June 3, 2013; revised July 3, 2013; accepted July 10, 2013

Copyright (C 2014 Paul Kah et al. This is an open access article distributed under the Creative Commons Attribution License, which permits unrestricted use, distribution, and reproduction in any medium, provided the original work is properly cited. In accordance of the Creative Commons Attribution License all Copyrights (C) 2014 are reserved for SCIRP and the owner of the intellectual property Paul Kah et al. All Copyright (C) 2014 are guarded by law and by SCIRP as a guardian.

\begin{abstract}
The level of automation in the manufacture of recreational aluminum boats is very low. Robotized welding is rarely utilized, although it is commonly considered as the most effective way to reduce costs and increase competitiveness. A reason for the under-exploitation of robotics can be found in the construction of aluminum boats; boat models and their detailed structures are almost without exception individual pieces. A new stiffener structure for an aluminum recreational boat hull is developed in this work. Construction of the stiffener as a module allows exploitation of the advantages of modularization. The number of different parts is reduced and the structure simplified improves the applicability of robotic welding and provides benefits accruing from mass production. The same module can be used in several boat models. The modularity also makes it possible to use the same advanced robot welding fixture for a variety of boat models.
\end{abstract}

\section{KEYWORDS}

Modularization; Modularity; DFMA; Design for Manufacture and Assembly; Aluminum Welding; Robotic Welding; Sub-Assembly; Boat

\section{Introduction}

Manufacturing industry in developed countries is under considerable strain. International competition is forcing companies to strive for better efficiency, reduced costs, increased quality, and reduced response time. At the same time, products should fulfill customer needs more effectively and a greater variety of products (i.e. customized products) should be available. These diverse requirements are to some extent conflicting. Modularization and automation can be seen as one of the most effective ways to increase the competitiveness of industrial companies. Modularization achieves this by bridging the advantages of standardization and rationalization with customization and flexibility [1]. Modularity can also be seen as a strategy to organize complex products and processes efficiently. A modular system is composed of units (or modules) that are designed independently but still function as an effective whole.

Welding automation and robotics are effective tools for production within the dynamic behavior of modern markets [2]. Robotic production set-ups exhibit the best "cost per unit" performance when compared with mass and low volume production, as shown in Figure 1. To keep manufacturing plants in high-cost developed countries and prevent further outsourcing and offshoring, manual work should be minimized and replaced with robotic approaches wherever possible. The manufacture of unsophisticated products with intensive manual work is drifting to low-salary regions of the world. To ensure large enough welding volumes for efficient utilization of robotic welding, products need to be constructed in such a way that the same parts can be used in several end products. By combining automation and modularization, the applicability of robots can be extended even to lowvolume production.

\subsection{Benefits of Modularization}

Traditionally, companies have chosen either mass pro- 


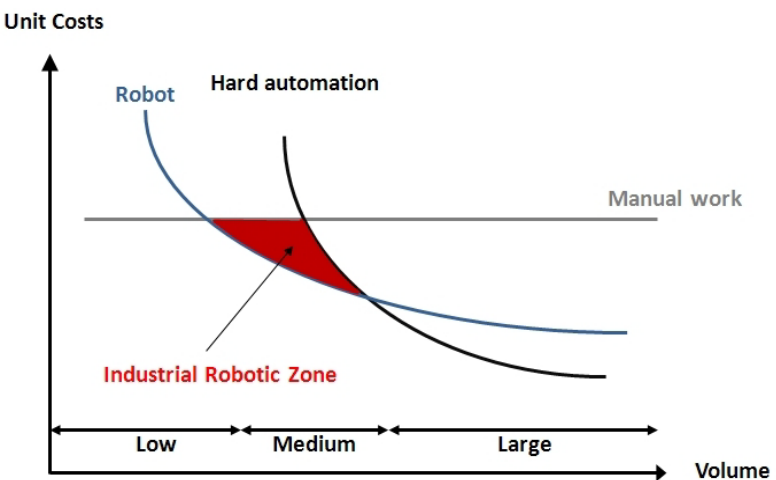

Figure 1. Area of robotic production as a function of production volume and unit costs [2].

duction (standardization) at the expense of customization or tailored production at the expense of efficiency. With modular products, individual customer needs can be fulfilled and tailored products are produced using standardized modules or their variations. The use of standardized modules allows the benefits of mass production to be better utilized. A decrease in the variation of parts required and the division of large products into sub-assemblies can ease the handling and manufacture of products. Furthermore, the manufacturing process can readily be divided into several working points.

Manufacturing and assembly advantages achieved by modularization are as follows [3]:

- Simultaneous manufacture of sub-assemblies becomes possible;

- The delivery cycle shortens because of simultaneous manufacturing;

- As a consequence of standardization, mass production becomes possible for separate sub-assemblies;

- The assembly time shortens because of a restricted number of modules and clear interfaces between modules;

- The independent testing of separate sub-assemblies becomes possible; and

- Sub-assemblies can be manufactured on the most suitable platform and transported to the assembly workshop.

\subsection{Limitations of Modularization}

Modularization does not always bring unambiguous benefits and possible compromises arising out of modularization need to be considered. In product design, the generation of the modules to a great extent defines the technical properties and geometry of the product. In addition, the redesign of a modularized product takes a long period of time and the design costs are high [4].

Although product tailoring can be increased by modularization, not all customer needs can be fully satisfied. Variations are limited to a combination of modules de- fined in advance. Excessive modularization can cause problems in the development stage of a product, where interfaces between the modules and parts are defined [5]. Product development becomes largely predictable and possibilities for revolutionary innovations are reduced. In addition, the predictability of product development increases the risk that competitors will launch a similar product on the market [6].

\subsection{Modularization in Robotic Welding}

Several different methods have been developed for the modularization process. Perhaps the best known are the MFD (Modular Function Deployment) and DSM (Design Structure Matrix) methods. Because MFD concentrates strongly on processability, it is better suited to the development of robotic welding, and it has thus been chosen as the method used in this study. MFD consists of five major steps [7]. It starts with quality function deployment (QFD) analysis to establish customer requirements and to identify important design requirements with a special emphasis on modularity. The functional requirements of the product are analyzed and technical solutions are selected. This is followed by a systematic generation and selection of modular concepts, in which a module indication matrix (MIM) is used to identify possible modules by examining the interrelationships between "module drivers" and technical solutions. The MIM also provides a mechanism for investigating opportunities of integrating multiple functions into single modules. The expected effects of the redesign can be estimated and an evaluation can be carried out for each modular concept. The MIM is then re-used to identify opportunities for further improvements to the single modules.

A very important aim of the last step is a reduction in the number of parts in the product or product family, because the number of parts has a remarkable effect on costs. For instance, material, labor and production costs are highly dependent on the quantity of parts [8].

In small series production, products are often welded manually, since investments in robotics need a large production volume to be economically profitable. However, by applying product modularization, similarities can be exploited and the number of standardized parts increases while maintaining small series production, which extends the series of welding sub-assemblies and distributes investment costs across several products.

The accessibility of the robot is an important issue in robotic welding. Especially in the case of box or enclosure type products, inner welds are often very difficult to access with a robot welding gun. A recommended solution is to divide the product into sub-assemblies or modules. Unfortunately, the product structure and welding cycle will then often become more complicated. 


\section{Case Study: Aluminum Boat}

Aluminum boats are very popular thanks to their durability, practicality, and seaworthiness. Light but durable aluminum material (typically alloy AW5754) tolerates shocks, scratches, and bottom contact without deforming or structural deterioration. It does not absorb water, nor does it bum, crack, fade or rust. Furthermore, it withstands extreme temperatures and weather, extending the boating season from early spring to late autumn in Nordic conditions. There are two different approaches in the construction of aluminum boats: either the hull is made of aluminum or it is a combination of aluminum and fiberglass. In both structures, the hull consists of bottom sheets, side enclosures, stiffeners, and a deck with or without a cabin. Side enclosures are made separately as sub-assemblies (either welded or riveted). They are packed with polyurethane to enable floating and prevent the boat from sinking should it become filled with water.

In the manufacture of a boat hull, the first step is to weld the bottom sheets. In upside-down position, the sheets are placed on top of a welding fixture (which gives a preliminary shape for the boat bottom) and butt welded. The side enclosures are connected to the bottom sheets using especially designed extruded profiles (AW6060). The profile has grooves for both the bottom sheet and the side enclosure, ensuring fluent positioning and easy welding. This profile also helps the boat to get on plane when boating. The last step in this position is to weld the transom on the hull. The boat is then turned in the normal position and inner welds are welded. The stiffener structure inside the hull consists of longitudinal and transversal stiffeners that are connected to each other by triangular brackets as shown in Figure 2 .

Finally, the boat is turned upside-down and long external welds (side enclosure/bottom sheets) are welded. In addition to this, some extra longitudinal L-profiles are

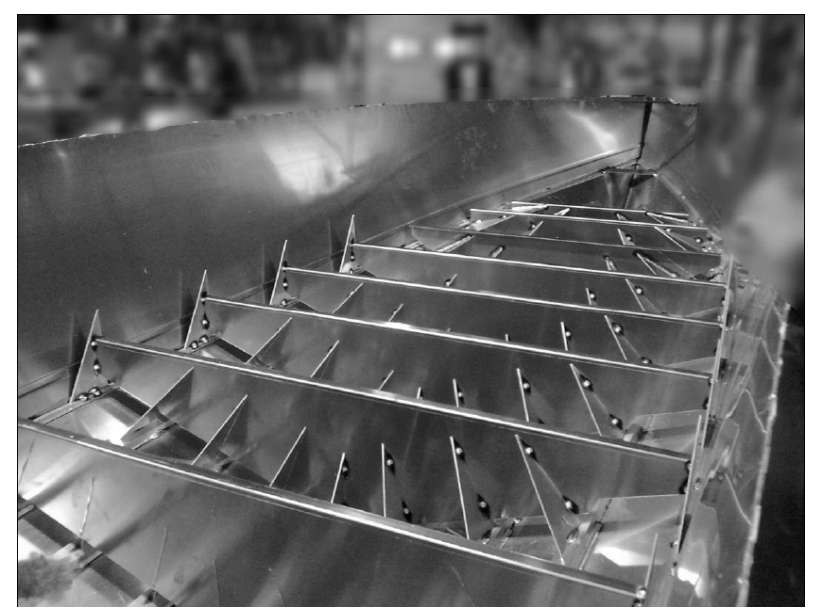

Figure 2. Hull of an aluminum boat and its internal stiffener structure. welded on the bottom sheets to help the boat to get on plane. Some face-welded joints are trimmed using the TIG process. An aluminum boat hull of the type studied here includes altogether 99 individual parts and the total weld length is 116 meters.

\section{Experiment and Results}

In the first stage, the old stiffener structure was examined from the point of view of robotic welding. The main problem is that accessibility for the robot welding gun is poor. There is not enough space inside the hull to operate robotic welding. The number of triangular brackets is very high and they are difficult to fix in the correct position for tack welding. The actual welds are short, because the brackets are welded to both the longitudinal and transversal stiffeners.

The modularization process was started using the MFD method. Because the product examined was already on the market, there was no need to go through all the steps of the method. The first two steps (customer requirements and technical solutions) had already been carried out during the boat's long product history and therefore this study did not cover them. Since the aim of the study was to enhance the use of robotic welding, the modularization process could be started straight from the manufacture base. The two MFD factors chosen were the "common unit" and "manufacturing process".

In "common unit", one or several modules will be created and later utilized in several boat models, as such or with minor modifications. The manufacturing process is robotic welding. Therefore, the requirements for robotic welding are carefully considered in the module design.

As mentioned earlier, the main problems in welding the old design can be found in the welding of stiffener welds inside the hull. Thus, a primary objective was to modulate the stiffener structure. As a design restriction, the boat shape and dimensions were fixed and could not be modified. The design was started based on a 3D model of the old boat hull. Catia V5 software was used for the modelling. As a solution, the large transversal structure was changed to a longitudinal structure. This gives more space for robot operations. The new stiffener structure or stiffener module is illustrated in Figure 3, on its own and as part of the entire boat hull.

The stiffener module consists of five longitudinal and eight transversal stiffeners. Each longitudinal stiffener is bent from the top to make the structure more rigid. For the transversal U-stiffeners, holes have to be cut on the longitudinal stiffeners using laser cutting. This helps the positioning of the parts and keeps the structure within geometrical tolerances.

A modular fixture was designed for robotic welding of the stiffener structure. This manually driven flexible fix- 


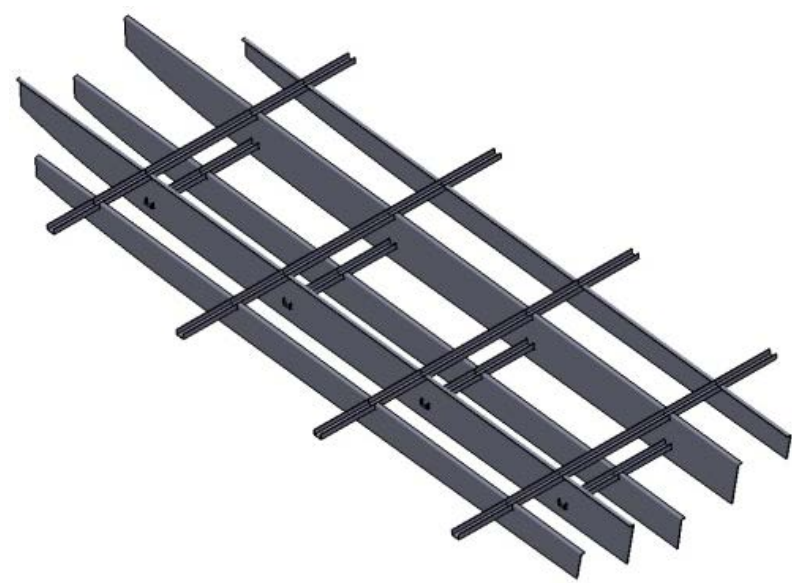

(a)

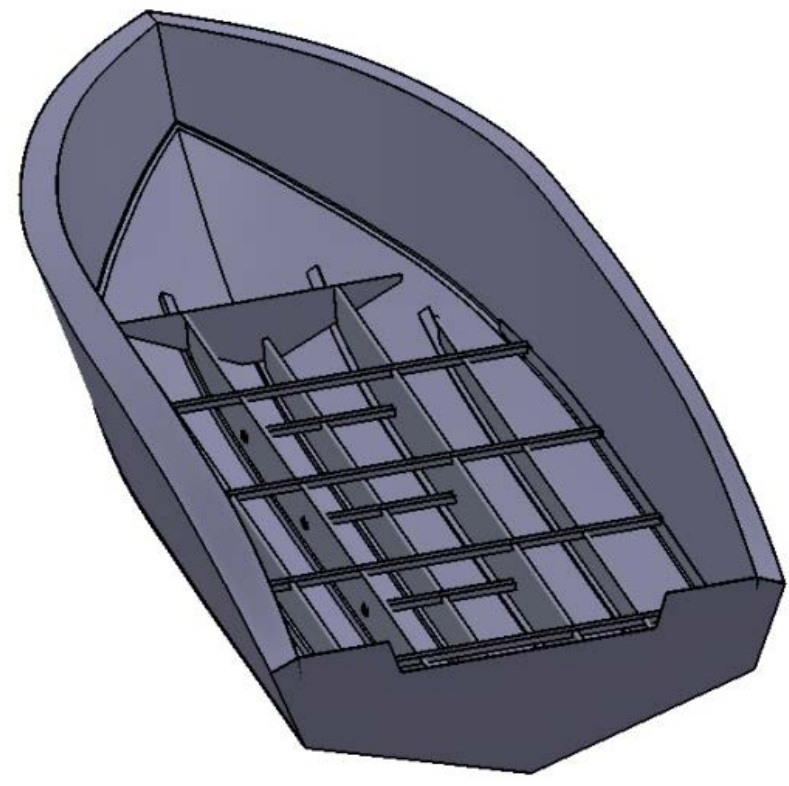

(b)

Figure 3. (a) New stiffener module and (b) the entire boat hull.

ture can be used for welding of the stiffener modules of several boat models by merely adjusting a few settings. Self-locating joints simplify the fixture structure considerably. Figure 4 illustrates the modular fixture alone and when attached to the robot welding station positioner. The parts of the stiffener module can be loaded on the fixture in a separate working point outside the robot welding station and no tack welding is needed. After the fixture has been clamped to the robot welding station positioner, the welding robot can reach all the welds and start the welding cycle.

To fully utilize the capacity of the robotic welding station, other welds of the boat's hull and their weldability were also examined. In practical welding experiments, a $1 \mathrm{~mm}$ air gap was the maximum permissible for high quality MIG fillet welds in $3 \mathrm{~mm}$ sheet plates.

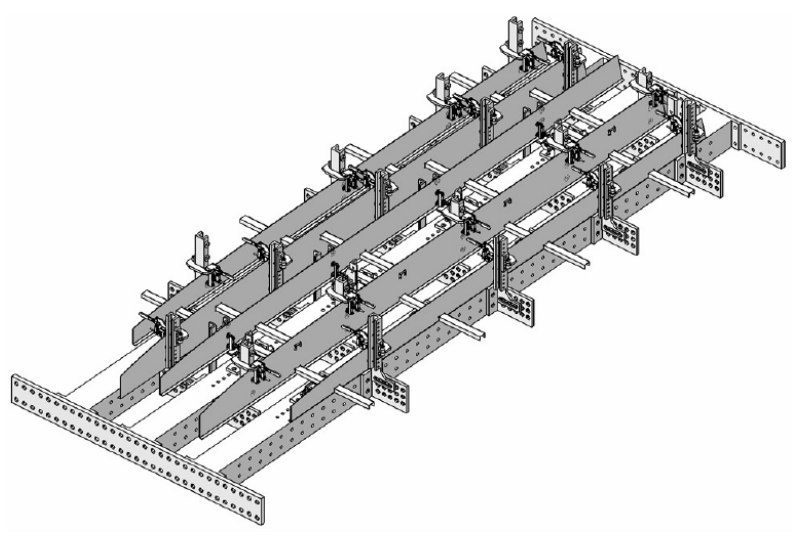

(a)

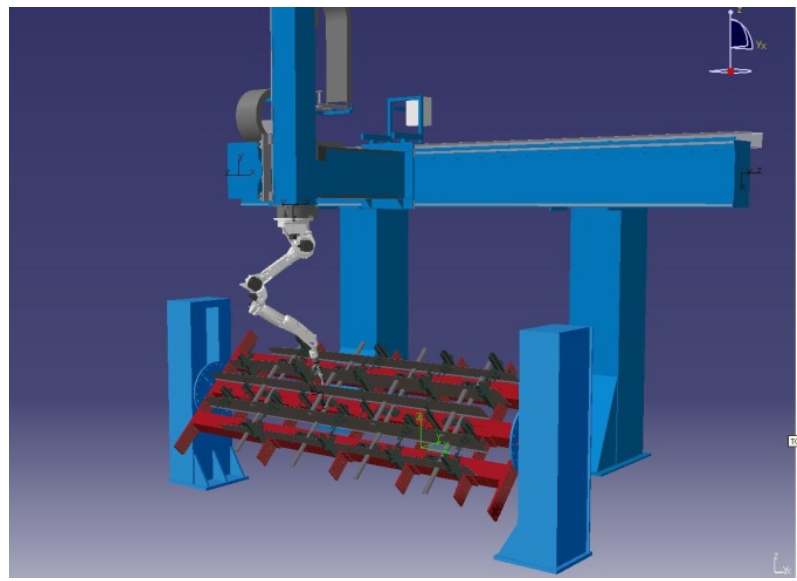

(b)

Figure 4. (a) Stiffener module chucked to the modular fixture and (b) Welding simulation in the robot welding station.

Based on these results, it is recommended that manual welding be used to fix the stiffener module to the hull. Inaccuracies in the shapes of the bottom sheets and the longitudinal U-profiles can exceed this value leading to poor fit up in robotic welding.

However, when welding the outer longitudinal fillet welds on the bottom side of the boat, robotic welding is strongly recommended. The robotic welding gun can reach all the welds easily and no accessibility problems exist.

The current stiffener structure contains 99 individual parts. In the new modulated structure, the number of parts is reduced to 31 parts. The reduction in the number of parts has a significant influence on the time consumed to pick up, locate, and fix them. In the new structure, this time is less than 4 minutes, whereas in the old structure this took up to 18 minutes. In reality, this time difference will be much bigger, because the current structure needs separate measuring instruments in order to locate parts in the correct positions. Assembling the new modulated structure is much faster, because the parts are located 
automatically in their correct positions thanks to the selflocating joints and welding fixtures. Furthermore, the parts are no longer tack welded prior to welding.

\section{Discussions}

The case study gives several implications inter-related in aspects of modularization and robotic welding of aluminum boat. To be explicit, manufacturability of the aluminum boat has been efficient and more so the weldability and time spent in robotic welding of the aluminum boat have improved through the means of modularization.

\subsection{Modularization}

Modularization such as in product design considerations for welding manufacturability can be used to develop different quantifiable modular structures applicable to wider range of boat sizes for either mass or customized products. Even though boat size can be determined by the manufacturer, practically boat size between 7 - 20 meters is suitable. It can be presumed that adapting modularization for development of structural sub-assemblies could increase product variations, decreasing unit cost and inventory management cost to boost productivity and profitability, improve competitiveness and also creating the possibility to manufacture and assemble through outsourcing.

\subsection{Design Method}

Evidently, the modular function deployment (MFD) design method used for the modularization process in the case study have therefore shown prospects by facilitating ease in manufacturability of structural members for building boats. As an example, the automotive industry is a beneficiary of modularization, thus sub-assemblies are used as platforms to aid manufacturability of diverse components such as car bodies [7]. Other products which could benefit from this design method through modularization processes include aircrafts, trains, motor cycles, etc.

However, the accessibility to robotically weld structural members and delays encountered during welding, which use to be ergonomic challenge in the case study, has been improved by means of the said design method. It could be assumed that the possibility of shorting lead times to about $40 \%$ or below is high as a result of eliminating space and positional constraints to enable robotic welding for boat building. This assumption somewhat corroborates with the finding that the duty cycle in hand welding is $10 \%-30 \%$ while mechanized and automated welding can be $70 \%$ - 90\% [9].

\subsection{Aluminum Boat}

Aluminum is suitable for boat building due to its advan- tageous characteristics such as high resistance to corrosion, low density, good strength and ductility properties, and also thermal and electrical conductivity.

However, due to the chemical and structural composition, many difficulties arise when welding aluminum. The oxide surface layer of aluminum impedes the flow of molten metal in the weld pool during welding and leads to the formation of very poor welds containing oxide inclusions. As aluminum is susceptible to hot cracking, a considerable drop in mechanical properties can occur in the welding zone. More so, aluminum has the tendency of absorbing high quantities of hydrogen when it melts, thus generating hydrogen porosity when the weld pool solidifies [10,11].

Although the compelling challenges such as manufacturability and accessibility associated with robotic welding of aluminum boat have been resolved in the case study, the need to examined automated welding processes in this case is imperative since groove position errors and joint configurations are significant in robotic welding. As reported, T-joints and fillet or over-lapping joints are more preferable and suitable joint configurations for robotic welding than corner and butt joints [12]. Thus attention must be paid to the suitability of the manufacturing processes used in the construction of aluminium boat.

\subsection{Robotic Welding}

As automated welding processes enhance productivity and weld quality, and in some cases lower manufacturing cost by eliminating the difficulties in welding aluminum, available welding techniques such as MIG, TIG, PAW and laser welding could be adapted for robotic welding in applications such as building of aluminium boats due to their advantages and disadvantages.

\subsubsection{MIG}

MIG, as used in the aforementioned experiment, is a common choice for robotic welding of aluminum. However, special control is needed when adapting the welding parameters for the welding steps: striking an arc, weld formation, arc end and burn back. Typical MIG automatized welding cells use a DC pulse power source, thus starting the arc can be the most difficult step [13]. On the other hand, AC pulse MIG welding is also used because of its reduced heat input without reducing the amount of deposit metal [14] and the reduced average temperature of the molten droplets transferred [15]. These characteristics make it useful to weld suitable for welding thin aluminum alloy sheets, for example, in the manufacturing of car bodies [16] and, as in the case under discussion here, aluminium boats. Automation of MIG for robotic welding results in higher welding speeds and current, which means less heat input, narrower heat 
affected zones (HAZ), less distortion, deeper penetration, less need for elaborate welding preparation, fewer weld passes and reduced porosity [17]. However, drawbacks are the need for more accurate and consistent weld preparations, more planning for realization of full benefits, and the need for capital expenditure to purchase manipulators and handling equipment [17]. DC pulsed MIG arc welding can also bring problems such as burn through, formation of holes in the bead and low gap tolerance when used to weld thin aluminum at high welding speeds (higher than $2 \mathrm{~m} / \mathrm{min}$ ) [16].

\subsubsection{TIG}

Automated TIG welding mostly uses Alternate Current TIG (AC-TIG) for aluminum because of the lack of oxide layer removal with DC electrode negative (DCEN) [17]. The benefits of aluminum TIG welding are high weld quality, good aesthetic appearance and the possibility to weld in all positions. The drawbacks are the need to provide the welding fixture with more accurate and consistent weld preparations than required in manual welding [17]. The slow speed, low deposition rate, and limited applicability for small material thickness limit its use.

\subsubsection{Plasma Arc Welding}

Plasma arc welding (PAW) is suited for automated welding of aluminum in a variable polarity mode [18], using the DCEN period to penetrate the workpiece and the DCEP period to remove the oxide film. Precise control of current and plasma gas flow rate are needed to maintain arc stability [18,19], keyhole and penetration stability [20]. It has been found to be difficult to achieve smooth transition from the start-up segment to the mainbody segment [21]. PAW has the advantage of an advanced level of control and accuracy, permitting welding at lower current levels than other arc welding processes. This process is especially advantageous in the welding of miniature components where the TIG arc start would damage the part [22].

\subsubsection{Laser Welding}

Aluminum is one of the most difficult materials to melt with lasers [23], due to the poor coupling, high thermal conductivity, high reflectivity and low boiling point [3]. As the wavelength of the laser increases, the coupling becomes poorer [24]. Considering laser sources for robotic welding of aluminum, $\mathrm{CO}_{2}$ laser welding has low flexibility due to the use of parabolic reflectors or transmissive systems for very concentrated beams with energy densities above $40 \mathrm{~kJ} / \mathrm{mm}^{2}$. $\mathrm{CO}_{2}$ laser welding is mostly used for butt welds [25]. In Nd:YAG laser welding, the wavelength of the light is ten times lower than a gas laser, so the solid state laser permits a better coupling of the beam with the parent metal. This also permits the laser light to be transmitted through fibre optics rather than requiring the use of copper mirrors as used to manipulate the light in the $\mathrm{CO}_{2}$ laser. Consequently, $\mathrm{Nd}$ : YAG laser welding has greatly improved flexibility, allowing the use of robotics [17]. The main drawback in laser welding of aluminum is porosity formation [26].

As most welding robots are "teach and playback" robots, sensor-based adaptive robotic welding is required. Sensing technology for robotic welding helps to overcome mismatch in welding variables, like errors in premachining, fitting of the work piece, in-process thermal distortions [27], correction for component tolerances, and fit-up variation. The sensing technology ensures that the weld path is optimized for each individual task [28].

However, adapting sensing techniques for robotic welding of aluminium can be difficult due to the high material reflectance [29], sensitivity to heat input and heat conduction [30], and difficulty in obtaining information from arc current data [31]. Continuous efforts are being undertaken to improve sensing and data acquisition and to develop effective sensing techniques for robotic welding of aluminium. Furthermore, to be able to take full advantage of adaptive robotic welding, suitable sensor-based technology is required. These sensing techniques include touch sensing, vision sensing, and composite sensing.

Touch sensing can be used for prior-to arc-start localization of the joint. Touch sensing is a low cost technology that does not require external hardware that might lower welding process flexibility [31]. Vision sensing has a wide number of uses in aluminium welding since it can be used prior to the arc start to locate the start of the weld and seam direction, and also to give real-time information about seam direction, penetration and weld pool geometry, and gap size [31,32].

\section{Conclusions}

The manufacture of aluminum boats is commonly done using traditional approaches and the level of automation of welding is very low. The reason for this is primarily the construction of boats, which poses challenges to robotic welding. However, individualized structures can be reconstructed in such a way that the principles of modularization can be utilized. Practical implications of such an approach are summarized in the following:

1) In the case studied here, the welding of the current stiffener structure takes about 75 minutes using the present manual working method. In the new structure developed in this study, the welding can be done using robots. In the first step, the stiffener structure is welded as a separate sub-assembly. The location of the assembly parts, fixing them in the welding fixture and the robotic welding will take about 20 minutes. The welded stiffener 
structure is then located and welded to the boat hull. This takes another 20 minutes. Thus, the total welding production time can be reduced by over $50 \%$. When taking into consideration that during the robotic welding of the stiffener module as a separate sub-assembly the boat hull can be built up simultaneously, the total delivery cycle of the boat hull can be reduced by 55 minutes. This is more than $10 \%$ of the total production time.

2) The accessibility of the new structure is much improved compared to the old structure. The longitudinal stiffener structure leaves more space for the welding gun near the welds. An additional optical sensor in the welding head could even be used. Only the welds in the rear end of the hull (transom) could not be accessed by the robotic welding gun.

3) Boat builders typically have parallel boat models with and without a cabin. In the old structures, the stiffener construction is very different for the two models. In the new construction method, the same stiffener structure can be used in both models. For models with a cabin, the only change required is that short pieces must be cut away from two transversal stiffeners in the prow to provide space for the corridor.

4) In this study, a sketch of a modular stiffener structure was composed. Because this was done primarily from the manufacturing point of view, additional research work is still needed, especially strength analysis, to ensure that this modular design fulfills the requirements of international marine standards (for instance, EN ISO 12215 Small craft, hull construction and scantlings).

\section{REFERENCES}

[1] D. T. Miller and P. Elgård, "Defining Modules, Modularity and Modularization-Evolution of the Concept in a Historical Perspective," Proceedings of the 13th IPS Research Seminar, Fuglsoe, 1998, 19 p.

[2] J. N. Pires, A. Loureiro and G. Bolmsjö, "Welding Robots: Technology, System Issues and Application,” Springer, London, 2006.

[3] J. Aarnio, "Modularization by Integration: Creating Modular Concepts for Mechatronic Products,” Ph.D. Thesis, Tampere University of Technology, Tampere, 2003.

[4] M. Hellström, "Business Concepts Based on Modularity: A Clinical Inquiry into the Business of Delivering Projects,” Ph.D. Thesis, Åbo Akademi University, Turku, 2006.

[5] T. Blecker, G. Friedrich, B. Kaluza, N. Abdelkafi and G. Kreutler, "Information and Management Systems for Product Customization,” Springer, Boston, 2004.

[6] L. Fleming and O. Sorenson, "The Dangers of Modularity,” Harvard Business Review, Vol. 79, No. 8, 2001, pp. 20-21.

[7] G. Erixon, "Modular Function Deployment-A Method for Product Modularization,” Ph.D. Thesis, The Royal Institute of Technology, Stockholm, 1998.
[8] A. Ericsson and G. Erixon, "Controlling Design Variants -Modular Product Platforms,” Society of Manufacturing Engineers, Dearborn, 1999.

[9] J. Lukkari, "Weld Deposition Rate and Its Uses,” Welding News, 2008, pp. 10-13.

[10] E. Craig, “The Plasma Arc Process-A Review,” Welding Journal, Vol. 2, 1988, pp. 19-25.

[11] W. Tuttle, “Understanding Aluminum Welding,” Welding Journal, Vol.70, 1991, pp. 43-46.

[12] H. Ahola, "Automated Arc Welding Taking into Account the Design of the Product," Technical Information 16/88. 1988, pp. 13-28.

[13] J. Hoffman, “The Challenges of Robotic Aluminum Gas Metal Arc Welding,” Weldingmag.com, 2007.

[14] H. Tong, T. Ueyama, S. Harada and M. Ushio, "Quality and Productivity Improvement in Aluminium Alloy Thin Sheet Welding Using Alternating Current Pulsed Metal Inert Gas Welding System," Science and Technology of Welding and Joining, Vol. 6, No. 4, 2001, pp. 203-208. http://dx.doi.org/10.1179/136217101101538776

[15] H. Tong, "Study on the Mechanism of Fume Formation in Pulsed MIG Welding of Al-Mg Alloy,” MEng Thesis, Welding Research Institute, Osaka University, Osaka, 1995.

[16] H. Tong, T. Ueyama, S. Harada and M. Ushio, "High Speed Welding of Aluminium Alloy Sheets with Using the Laser/AC Pulsed MIG Hybrid Process," Science and Technology of Welding and Joining, Vol. 8, 2003, pp. 229-234. http://dx.doi.org/10.1179/136217103225010853

[17] G. Mathers, "Welding of Aluminum and Its Alloys," Woodhead Publishing, Sawston, 2002.

[18] B. Zheng, "The Discontinuous Pilot Power Source for AC PAW,” China Weld, Vol. 6, 1995, pp. 1-6.

[19] B. Zheng, Q. L. Wang and R. Kovacevic, "Arc Interference and a Unique Push-Pull-Arc Solution in Alternating Current Plasma Arc Welding of Aluminum Alloys," Journal of Engineering Manufacture, Vol. 213, No. 1, 1999, pp. 69-76.

[20] H. D. Steffens, Welding Journal, Vol. 6, 1972, pp. 40-45.

[21] B. Zheng, Q. L. Wang and R. Kovacevic, "Parameters Optimization for the Generation of a Keyhole Weld Pool during the Start-Up Segment in Variable-Polarity Plasma Arc Welding of Aluminium Alloys,” Journal of Engineering Manufacture, Vol. 214, No. 5, 2000, pp. 393-400.

[22] B. Mannion and J. Heinzman, "Plasma Arc Welding Brings Better Control," Tooling and Production, Vol. 5, 1999, pp. 29-30.

[23] C. A. Huntington and T. W. Eagar, "Laser Welding of Aluminum and Aluminum Alloys," Welding Research Supplement, Vol. 62, 1983, pp. 105-107.

[24] M. A. Bramson, "In Infrared Radiation," Handbook for Applications, Plenum Press, New York, 1968, p. 107

[25] J. Weston, J. W. Yoon and E. R. Wallach, "Laser Welding of Aluminum Alloy using different Laser Sources," TWI, 2003.

[26] A. Ascari, A. Fortunato and G. C. Leonardo Orazi, “The 
Influence of Process Parameters on Porosity Formation in Hybrid LASER-GMA Welding of AA6082 Aluminum Alloy,” Optics \& Laser Technology, Vol. 44, No. 5, 2012, pp. 1485-1490.

http://dx.doi.org/10.1016/j.optlastec.2011.12.014

[27] H. Shen, J. Wu, T. Lin and S. Chen, “Arc Welding Robot System with Seam Tracking and Weld Pool Control Based on Passive Vision," The International Journal of Advanced Manufacturing Technology, Vol. 39, No. 7-8, 2008, pp. 669-678. http://dx.doi.org/10.1007/s00170-007-1257-8

[28] J. Mortiner, “Jaguar Uses Adaptive MIG Welding to Join C-Pillars to an Aluminium Roof Section in a New Sports Car,” Sensor Review, Vol. 26, No. 4, 2006, pp. 272-276. http://dx.doi.org/10.1108/02602280610691971

[29] X. Chen, S. Chen and T. Lin, "Practical Method to Locate the Initial Weld Position Using Visual Technology,” The International Journal of Advanced Manufacturing Technology, Vol. 30, No. 7-8, 2006, pp. 663-668.

[30] C. Fan, F. Lv and S. Chen, "Visual Sensing and Penetration Control in Aliminum Alloy Pulsed GTA Welding," International Journal of Manufacturing Technology, Vol. 42, No. 1-2, 2009, pp. 126-137.

[31] E. O’Shea, “Comparing Intelligent Robotic Arc-Sensing Technologies,” Penton's Welding Magazine, Vol. 82, No. 6, 2009, pp. 14-17.

[32] J. J. Wang, T. Lin and S. B. Chen, "Obtaining Weld Pool Vision Information during Aluminum Alloy TIG Welding,” International Journal of Manufacturing Technology, Vol. 26, No. 3, 2005, pp. 219-227. 